\title{
COMPOSIÇÃO DO LEITE COM INSTABILIDADE DA CASEÍNA ${ }^{1}$
}

\author{
Daniela S. OLIVEIRA², Cláudio D. TIMM ${ }^{2, *}$
}

\section{RESUMO}

No presente trabalho, foi determinada a composição do leite não ácido e não mastítico com instabilidade da caseína em propriedades leiteiras do município de Santa Vitória do Palmar, Rio Grande do Sul, Brasil, entre abril de 2002 e março de 2003. Foram realizados titulação da acidez, contagem de células somáticas (CCS), para descartar leites com caseína instável devido à acidez adquirida ou mastite, teste do álcool e determinação dos teores de gordura, lactose, proteína e sólidos totais. Amostras com resultado positivo no teste do álcool, CCS menor que $1,28 \times 10^{6} \mathrm{~mL}^{-1}$ e acidez menor que $18^{\circ} \mathrm{D}$ foram consideradas com instabilidade da caseína. O teor de gordura do leite com instabilidade da caseína $(3,30 \%)$ foi significativamente maior que o do leite normal (3,04\%). A lactose apresentou teores menores no leite com instabilidade da caseína (4,16\%) do que no leite normal $(4,33 \%)$. Os teores de proteína e de extrato seco total não apresentaram variação significativa. No outono, houve elevação do teor de gordura no leite com instabilidade da caseína.

Palavras-chave: caseína, instabilidade, composição, leite.

\section{SUMMARY}

COMPOSITION OF MILK WHIT CASEIN INSTABILITY. In the present study, it was determined the composition of milk non-acid and non-mastitic with casein instability from dairy farms of Santa Vitória do Palmar, Rio Grande do Sul, Brazil, between April 2002 and March 2003. The samples were subjected to titratable acidity, somatic cell count (SCC), to discard milk with casein instability due to acquired acidity or mastitis; alcohol test and fat, protein, lactose and total solids contents. The samples with positive alcohol tests, SCC lesser than $1.28 \times 10^{6} \mathrm{~mL}^{-1}$ and acidity lesser than $18^{\circ} \mathrm{D}$ were considered as milk with casein instability. The mean of fat content of instable milks $(3.30 \%)$ was significantly higher than that of normal milk (3.04\%). Lactose content was lower in instable milks (4.16\%) than in normal milks (4.33\%). Protein and total solids contents not showed significant difference between normal milk and instable milk. During autumn, the rates of fat content in milk with casein instability were higher than in the other seasons.

Keywords: casein, instability, composition, milk.

\section{1 - INTRODUÇÃO}

O leite bovino é um líquido complexo que contém água, glicídios (basicamente lactose), gorduras, proteínas (principalmente caseína), minerais e vitaminas em diferentes estados de dispersão [24].

Provas simples de rotina, como a do álcool, são utilizadas em indústrias de laticínios para avaliar a estabilidade da caseína do leite ao tratamento térmico ou ao $\mathrm{pH}$. Inicialmente, a prova do álcool foi utilizada pela indústria láctea como uma medida indireta do $\mathrm{pH}$ natural do leite, pela relação que existe entre ambos os parâmetros: a acidez produz perda da estabilidade, podendo provocar a precipitação da proteína [5].

A acidez não é o único fator que provoca instabilidade da caseína. Processos inflamatórios na glândula mamária aumentam a concentração de plasmina no leite, cuja ação

\footnotetext{
${ }^{1}$ Recebido para publicação em 18/05/2004. Aceito para publicação em 28/04/2006 (001350)

${ }^{2}$ Inspeção de Leite e Derivados, Faculdade de Veterinária, Universidade Federal de Pelotas, campus universitário, prédio 34, Pelotas (RS) CEP 96020-380

*A quem a correspondência deve ser enviada
}

hidrolítica sobre a caseína leva à diminuição da estabilidade [17, 21]. Embora as causas não estejam ainda bem esclarecidas, diversos autores têm registrado a ocorrência de instabilidade da caseína em leites com acidez normal e baixa contagem de células somáticas (CCS) [3, 9, 16, 22, 23]. Entretanto, poucos são os estudos sobre a composição do leite nestas condições.

PECORARI et al. [15], analisando leite com coagulação anormal, encontraram valores baixos para acidez titulável e teores de caseína, cálcio e fósforo, e valores elevados para $\mathrm{pH}$ e teor de ácido cítrico.

PONCE [18], estudando alterações no leite produzido em Cuba, observou diminuição dos sólidos do leite (proteína bruta, caseína, lactose e minerais), alterações em suas propriedades, como baixa acidez titulável, alto $\mathrm{pH}$, resultado positivo na prova do álcool, alterações no equilíbrio mineral, e problemas na industrialização, como precipitação durante a pasteurização, baixo rendimento na fabricação do queijo, aumento do tempo de coagulação, maior fragilidade do coágulo e possibilidade de precipitações para o leite tipo UHT. Esses fenômenos ocorreram com maior freqüência durante a época de seca e nas zonas do país onde são exploradas as raças leiteiras mais especializadas. 
Alta freqüência de casos de leites oriundos de animais sadios que reagem positivamente à prova do álcool, sem apresentarem acidez titulável elevada, tem sido observada na região sul do Rio Grande do Sul [22]. A caracterização da composição do leite não ácido e não mastítico com instabilidade da caseína, identificando as épocas e condições em que é observada, é fator fundamental para o controle dessas alterações que têm causado problemas para a produção de leite com qualidade.

\section{2 - MATERIAL E MÉTODOS}

\section{1 - Amostras de leite}

De abril de 2002 a março de 2003, foram coletadas diretamente dos tanques de resfriamento de estabelecimentos produtores de leite do município de Santa Vitória do Palmar, no extremo sul do Brasil, 282 amostras de leite cru. Foram obtidas uma ou duas amostras de 52 propriedades no outono, 42 no inverno, 44 na primavera e 44 no verão. Os rebanhos das propriedades eram constituídos por animais das raças Holandês, Jersey e mestiços.

O município de Santa Vitória do Palmar é caracterizado por possuir campos com elevado número de espécies rizomatosas e cespitosas de baixo porte que formam excelentes pastagens. São campos limpos e planos, onde surgem espécies de leguminosas de ótimo valor forrageiro, dos gêneros Adesmia (babosa), Demodium (pega-pega), Laeersia hexandra (grama boiadeira) e Phaseolus prostratus (feijãozinho).

Durante o período do inverno, as áreas de campo são reduzidas em virtude da crescente das lagoas (Mirim, Mangueira e outras menores) e da topografia plana [14]. O volume de leite produzido no município nos meses em que foi realizado o experimento foi de: $252.657,178.392$, 168.380, 161.585, 175.047, 246.340, 315.211, 308.946, 303.353, 315.518, 252.664 e 254.096 L, nos meses de abril de 2002 a março de 2003, respectivamente [2].

O número médio de vacas em lactação era 23 por propriedade. A alimentação dos animais, no inverno, na maioria das propriedades, era baseada em consórcio de trevo branco, azevém e cornichão. Alguns produtores plantavam aveia para corte e alguns também ofereciam concentrados, em média $3 \mathrm{~kg} /$ dia/vaca. Na primavera e no verão, eram oferecidos o consórcio e as pastagens nativas. No outono, a alimentação baseava-se em resteva de arroz e pastagens nativas.

\section{2 - Análise dos teores de gordura, lactose, sólidos totais e proteína}

As amostras de leite foram acondicionadas em frascos contendo conservante Bronopol (2-bromo-2-nitropropano1,3-diol) e transportadas em caixas isotérmicas com gelo ao laboratório para determinação dos teores de gordura, proteína, lactose e sólidos totais pelo método infraverme- lho, segundo ASSOCIATION OF OFFICIAL ANALITICAL CHEMIST [1].

As amostras que não apresentaram teores de gordura de 2 a $5 \%$ foram desconsideradas. Segundo DÜRR, FONTANELI \& MORO [11], os resultados de análise com teores de gordura abaixo de $2 \%$ e acima de $5 \%$ devem ser descartados, por indicarem erros de coleta. Os glóbulos de gordura, por estarem suspensos na água e por apresentarem uma densidade inferior a essa, irão concentrar-se na camada superior da massa de leite resfriado, devendo ser feita a homogeneização no momento da coleta. Os demais componentes não são tão afetados pela falta de homogeneização do leite quanto à gordura, o que torna este componente o principal indicador de problemas de amostragem.

\section{3 - Caracterização do leite com instabilidade da caseína}

As amostras foram testadas na prova do álcool, misturando-se $2 \mathrm{~mL}$ da amostra com $2 \mathrm{~mL}$ de etanol a 70\%, para a verificação da estabilidade da caseína. As amostras com resultado positivo, representado pela formação de grumos, foram consideradas com caseína instável. Para descartar leites com caseína instável devido à acidez adquirida ou à mastite, foram consideradas apenas as amostras com acidez até $18^{\circ} \mathrm{D}$ e CCS abaixo de $1,28 \times 10^{6} \mathrm{~mL}^{-1}$.

\section{4 - Caracterização do leite normal}

Foram consideradas amostras de leite normal, aquelas que apresentaram acidez titulável entre 14 e $18^{\circ} \mathrm{D}$, resultado negativo na prova do álcool e CCS menor ou igual a $5,0 \times 10^{5} \mathrm{~mL}^{-1}$.

\section{5 - Análise estatística}

As médias dos resultados dos diversos componentes do leite com instabilidade da caseína e do leite normal foram avaliadas estatisticamente pelo Teste $t$ de Student $(\mathrm{p}<0,01)$, com distribuição bi-caudal e variância desigual de duas amostras, através do programa Microsoft Excel, versão 97.

A distribuição da freqüência de leite com instabilidade da caseína e do leite normal nas estações do ano foi avaliada com o uso do programa Epi Info, versão 6.04 [8].

\section{3 - RESULTADOS E DISCUSSÃo}

\section{1 - Composição do leite com instabilidade da caseína e do leite normal}

Os resultados obtidos na análise da composição do leite com instabilidade da caseína e do leite normal estão demonstrados na Tabela 1 . 
TABELA 1 - Composição do leite com instabilidade da caseína e do leite normal, coletados no município de Santa Vitória do Palmar, no período de abril de 2002 a março de 2003

\begin{tabular}{lcc}
\hline Componentes & $\begin{array}{c}\text { Leite com instabilidade } \\
\text { da caseína }\end{array}$ & Leite normal \\
\hline Gordura (\%) ${ }^{*}$ & 3,30 & 3,04 \\
Proteína (\%) ${ }^{\text {ns }}$ & 2,89 & 2,91 \\
Lactose (\%) $^{*}$ & 4,16 & 4,33 \\
Sólidos Totais (\%) ${ }^{\text {ns }}$ & 11,25 & 11,17 \\
\hline
\end{tabular}

*Diferença significativa entre as médias $(\mathrm{p}<0,01)$

ns - não significativo

O componente do leite que apresentou maior variabilidade foi a gordura, havendo um aumento significativo $(\mathrm{p}<0,01)$ da média dos teores de gordura do leite normal $(3,04 \%)$ em relação a do leite com instabilidade da caseína $(3,30 \%)$. Por outro lado, o leite normal apresentou teores médios de lactose $(4,33 \%)$ significativamente $(\mathrm{p}<0,01)$ mais elevados que a média da lactose do leite com instabilidade da caseína ( $4,16 \%)$. Outros autores têm obtido resultados similares. BARROS et al. [4], estudando as variações do leite individual em função da positividade à prova do álcool, encontram para teores de gordura e lactose, respectivamente, médias de 3,95\% e 4,65\%, para resultados positivos, e de $3,40 \%$ e $4,84 \%$, para resultados negativos.

PONCE \& HERNÁNDEZ [19] observaram aumento nos teores de gordura e diminuição nas concentrações de lactose no leite após a reprodução experimental de um quadro de síndrome do leite anormal (SILA). As alterações observadas na composição do leite com caseína instável, no presente trabalho, são sugestivas de que os animais que produziram este leite receberam alimentação rica em volumosos. De acordo com HARRIS \& BACHMAN [13], o fator que mais interfere no percentual de gordura do leite é o teor de fibra da dieta ou a relação volumoso/concentrado. Assim, quanto maior o teor de fibra na alimentação, maior o teor de gordura do leite, devido à variação na proporção de ácidos graxos voláteis produzidos no rúmen. Uma maior ingestão de fibra aumenta a produção de ácido acético e reduz a produção de ácido propiônico.

O ácido acético é um dos principais precursores da gordura do leite e seu acréscimo está diretamente relacionado com o aumento desta no leite [16]. A maior produção e absorção de ácido acético no rúmen estão associadas com aumento da concentração de acetato no plasma e com aumento na secreção de água, proteína e gordura, como resultado da função do acetato como fonte de energia [6]. Portanto, uma alimentação rica em fibras explicaria as alterações de composição observadas e, conseqüentemente, levantaria a hipótese da ligação deste tipo de alimentação com a ocorrência de instabilidade da caseína, possivelmente através de desequilíbrios minerais que provocariam alterações iônicas no leite.

A composição do leite com caseína estável é sugestiva, devido aos mecanismos metabólicos mencionados, de que os animais que o produziram tenham recebido suplementação com concentrados, em geral melhor balanceados, o que permitiria a produção de leite com equilíbrio iônico normal e com caseína estável. Esta hipótese é corroborada pelo estudo de RODAS et al. [20], que, trabalhando com rebanhos suplementados e não suplementados com alimento concentrado, observaram que o leite proveniente do rebanho que não recebeu suplementação apresentou positividade no teste do álcool, com a acidez variando de $14^{\circ} \mathrm{D}$ a $15^{\circ} \mathrm{D}$.

Não houve diferença estatisticamente significativa entre o teor de proteína do leite normal $(2,91 \%)$ e do leite com instabilidade da caseína (2,89\%). Estes resultados diferem dos obtidos por BARROS et al. [5] que encontraram diferença significativa entre o teor de proteína em amostras negativas no teste do álcool, com média de 3,23\%, e positivas, com média de $3,49 \%$. É possível que, como o conteúdo protéico do leite não é tão variável quanto a gordura, os fatores que promoveram a elevação desta, não tenham sido suficientemente fortes a ponto de alterar os teores de proteína do leite com caseína instável. Também não houve diferença significativa entre o teor de extrato seco total do leite normal ( $11,17 \%)$ e do leite com instabilidade da caseína ( $11,25 \%)$, o que pode ser explicado pela compensação da queda no teor de lactose pelo aumento no teor de gordura.

\section{2 - Composição do leite com instabilidade da caseína e do leite normal nas estações do ano}

No outono houve maior percentagem de gordura $(3,45 \%)$, de proteína (2,98\%) e de sólidos totais $(11,50 \%)$ no leite com instabilidade da caseína, em relação às outras estações. Ocorreu um aumento da percentagem de lactose $(4,30 \%)$ no inverno. As menores percentagens dos componentes do leite com instabilidade da caseína ocorreram na primavera com médias de 2,87\%, 2,74\%, 3,96\% e 10,39\% para teor de gordura, caseína, lactose e sólidos totais, respectivamente (Tabela 2 ).

TABELA 2 - Composição do leite com instabilidade da caseína durante as estações do ano, coletados no município de Santa Vitória do Palmar, no período de abril de 2002 a março de 2003

\begin{tabular}{lcccc}
\hline Componentes & Outono & Inverno & Primavera & Verão \\
\hline Gordura (\%) & 3,45 & 3,22 & 2,87 & 3,26 \\
Proteína (\%) & 2,98 & 2,78 & 2,74 & 2,84 \\
Lactose (\%) & 4,16 & 4,30 & 3,96 & 4,19 \\
Sólidos totais (\%) & 11,50 & 11,22 & 10,39 & 11,09 \\
\hline
\end{tabular}

O componente do leite com instabilidade da caseína que apresentou maior variação em relação à estação, foi a gordura. O aumento dos teores de gordura, proteína e sólidos totais no leite com instabilidade da caseína durante o outono pode ser devido aos animais receberem, em muitas propriedades, nesta época do ano, alimentação à base de volumosos (resteva de arroz e pastagem nativa), sem suplementação com concentrados.

No leite normal, o teor de gordura apresentou aumento no inverno $(3,08 \%)$ e na primavera $(3,07 \%)$ e diminuiu 
no verão (2,97\%); o teor de proteína aumentou no outono $(2,99 \%)$ e diminuiu no inverno $(2,81 \%)$; o teor de lactose apresentou aumento no inverno e no verão $(4,34 \%)$ e diminuiu na primavera $(4,31 \%)$. Os sólidos totais aumentaram no outono $(11,26 \%)$ e diminuíram no verão (11,09\%) (Tabela 3).

TABELA 3 - Composição do leite normal durante as estações do ano, no município de Santa Vitória do Palmar, no período de abril de 2002 a março de 2003

\begin{tabular}{lcccc}
\hline Componentes & Outono & Inverno & Primavera & Verão \\
\hline Gordura (\%) & 3,01 & 3,08 & 3,07 & 2,97 \\
Proteína (\%) & 2,99 & 2,81 & 2,90 & 2,91 \\
Lactose (\%) & 4,33 & 4,34 & 4,31 & 4,34 \\
Sólidos totais (\%) & 11,26 & 11,16 & 11,14 & 11,09 \\
\hline
\end{tabular}

O aumento do teor de gordura no outono, observado no leite com caseína instável, não foi evidenciado no leite normal, o que está de acordo com os resultados encontrados por DÜRR et al. [10], que observou, no Rio Grande do Sul, percentuais de gordura superiores no inverno, quando comparados às demais épocas do ano. A gordura é o componente mais variável do leite [12], porém há uma relação negativa entre a gordura e a produção de leite. O aumento no volume de leite produzido leva à diluição da gordura, mesmo que sua síntese esteja favorecida por fatores alimentares, que também aumentam a produção de leite, resultando em uma redução dos percentuais de gordura [7]. Provavelmente, o leite normal seja oriundo de estabelecimentos onde o manejo nutricional esteja mais adequado, melhor balanceado, não ocorrendo aumento no teor de gordura de leite com instabilidade da caseína e de leite normal na mesma época do ano.

\section{4 - CONCLUSÕES}

O leite com caseína instável apresentou maiores teores de gordura e menores teores de lactose que o leite com caseína estável. Estas alterações na composição do leite são características de animais alimentados basicamente com dietas fibrosas, o que é reforçado pelo elevado teor de gordura no leite com caseína instável durante o outono, quando é comum na região a alimentação baseada em restevas de lavoura de arroz e campos nativos. O mesmo não ocorreu com o leite com caseína estável, que apresentou teores de gordura mais altos no inverno.

Os resultados são sugestivos de que a relação observada entre instabilidade da caseína e alterações na composição do leite seja devida ao manejo alimentar, possivelmente envolvendo nutrientes necessários ao equilíbrio iônico do leite, fundamental para a estabilidade da caseína. Novos estudos são necessários para determinar quais são os componentes nutricionais envolvidos e quais os mecanismos que levam a perda da estabilidade do leite.

\section{5 - REFERÊNCIAS BIBLIOGRÁFICAS}

[1] A.O.A.C. ASSOCIATION OF OFFICIAL ANALITICAL CHEMIST. Official Methods of Analysis 972 , Washington, D.C., Association of Official Analitical Chemist, $16^{\text {th }}$ ed., 1972.

[2] AMARAL, R. Comunicação pessoal, Santa Vitória do Palmar (RS), 2003.

[3] BARROS, L.; DENIS, N.; GONZALEZ, A.; NUÑEZ, A. Ionized calcium related to alcohol test in milk. In: $10^{\text {th }}$ International Conference on Production Diseases in Farm Animals, 1998, Utrecht. Anais... Utrecht, 1998.

[4] BARROS, L.; DENIS, N.; NÚNES, A.; GONZÁLEZ, O.; GALIN, C.; TORRES, E.; GONZÁLEZ, P. Variaciones de la leche y prueba del alcohol, 2000, Punta del Este. In: XXI World Buiatrics Congress, Anais... Punta del Este, 2000, p. 577.

[5] BARROS, L. Transtornos metabólicos que afetam a qualidade do leite. In: Uso do leite para monitorar a nutrição e o metabolismo de vacas leiteiras, 2001, Passo Fundo. Anais... Porto Alegre: UFRGS, 2001, p. 44-57.

[6] CARVALHO, I.C. Modificações na composição do leite. Revista do Instituto de Laticínios Cândido Tostes, v. 32, n. 192, p. 15-26, 1977.

[7] CARVALHO, M.P.; FONSECA, L.F.L.; PEREIRA, C.C. Manipulação nutricional da composição do leite: proteína e gordura. In: IV Simpósio Internacional sobre produção intensiva de leite, 1999, Caxambu. Anais... São Paulo: Instituto Fernando Costa, 1999, p. 19-35.

[8] DEAM. A.G.; DEAM. J.A.; COUMOBIER, D.; BRENDEL, K.A.; SMITH, D.C.; BURTON, A.H.; DICKER, R.C.; SULLIVAN, K.; FAGAN, R.F.; ARNER, T.J. EPI Info Version 6.04. A word processing, database, and statistics program for epidemiology on microcomputers. Center for Disease Control and Prevention, Atlanta, G.A, 1994.

[9] DONATELE, D.M.; VIEIRA, L.F.P.; FOLLY, M.M. Relação do teste de alizarol $72 \%$ (v/v) em leite in natura de vaca com acidez e contagem de células somáticas: análise microbiológica. Hig. Alim., v. 17, n. 110, p. 95-100, 2003.

[10] DÜRR, J.W.; WEISS, T.B.; MORO, D.V.; SHLZ, J.G.; FONTANELI, R.S. Monitoramento da qualidade do leite cru na região de Santa Rosa, RS. In: $36^{a}$ Reunião anual da SBZ, Porto Alegre, 1999. Anais... Porto Alegre: Sociedade Brasileira de Zootecnia, 1999.

[11] DÜRR, J.W.; FONTANELI, R.S.; MORO, D.V. Determinação laboratorial dos componentes do leite. In: GONZÁLEZ, F.H.D.; DÜRR, J.W.; FONTANELI, R.S. (ed.) Uso do leite para monitorar a nutrição e o metabolismo de vacas leiteiras. Porto Alegre: UFRGS, p. 23-29, 2001.

[12] GONZÁLEZ, F.H.D. Composição bioquímica do leite e hormônios da lactação. In: GONZÁLEZ, F.H.D.; DÜRR, J.W.; FONTANELI, R.S. (ed.) Uso do leite para monitorar a nutrição e o metabolismo de vacas leiteiras. Porto Alegre: UFRGS, p. 5-22, 2001.

[13] HARRIS Jr., B.; BACHAMAN, K.C. Nutritional and management factors affecting solid-non-fat, acidity and freezing point of milk. Gainesville, Institute of Food and Agricultural Sciences, Florida Cooperative Extension Service, 1988. 
[14] MOHRDIECK, K.H. Formações campestres do Rio Grande do Sul. In: IV FEDERACITE (org.) Campo Nativo: melhoramento e manejo, Porto Alegre: Caramuru, 1993, p. 11-31.

[15] PECORARI, M.; FOSSA, E.; AVANZINI, G.; MARIAN, P. Milk with abnormal coagulation: Acidity, chemical composition and observation on the metabolic profile of the cow. Sci. Tec. Latt. Cãs., XXXV, n. 4, 1984. p. 263-278.

[16] PEREZ, J.R. O leite como ferramenta do monitoramento nutricional. In: GONZÁLEZ, F.H.D.; DÜRR, J.W.; FONTANELI, R.S. (ed.) Uso do leite para monitorar a nutrição e o metabolismo de vacas leiteiras. Porto Alegre: UFRGS, p. 30-45, 2001.

[17] PHILPOT, W.N. Programas de qualidade do leite no mundo. In: Simpósio internacional sobre qualidade do leite, 1998, Curitiba. Anais... Curitiba, 1998, p. 16.

[18] PONCE, P. Caracterização da síndrome do leite anormal: um enfoque das suas possíveis causas e correção. In: $4^{\circ}$ Simpósio Internacional sobre Produção Intensiva de Leite, 1999, Caxambu. Anais... São Paulo: Instituto Fernando Costa, 1999, p. 61-76.

[19] PONCE, P.; HERNÁNDEZ, R. Propriedades físicoquímicas do leite e sua associação com transtornos metabólicos e alterações na glândula mamária. In: GONZÁLEZ, F.H.D.; DÜRR, J.W.; FONTANELI, R.S. (ed.) Uso do leite para monitorar a nutrição e o metabolismo de vacas leiteiras. Porto Alegre: UFRGS, p. 61-72, 2001.

[20] RODAS, A.C.; ISEPON, J.S.; ALVES, J.B.; ISEPON, O.J. Monitoramento na qualidade do leite "in natura" obtidos por diferentes tipos de manejo em Pereira Barreto (SP), Revista do Instituto de Laticínios Cândido Tostes, v. 54, n. 312, p. 19-29, 2000.

[21] SILVA, P.H.F.; ALMEIDA, M.C.F. Estabilidade térmica do leite. Trabalho realizado na EPAMIG-Centro Tecnológico/Instituto de Laticínios Cândido Tostes. Disponível em: http://www.atrius.com.br/downlod/ estab.\%20\%E9rmica\%20\%.\%20artigo.doc. Acesso em: 10 set. 2003.

[22] TIMM, C.D.; OLIVEIRA, D.S.; ARRIADA, E.O.; MORAES, C.M.; ROOS, T.B.; GONZALEZ, H.L. Estabilidade protéica do leite produzido no município de Santa Vitória do Palmar. In: XXIX Congresso Brasileiro de Medicina Veterinária, 2002, Gramado. Anais... Gramado: Sociedade Brasileira de Medicina Veterinária, 2002. cd-rom.

[23] YOSHIDA, S. Studies in the Utretch abnormality of milk in the Miyuki Dairy Farm. J. Jap. Appl. Biol. Sci. Hir. Univ., v. 19, 1980, p. 39-54.

[24] WALSTRA, P.; JENNESS, R. Química y física lactológica. Zaragoza: Editorial Acribia, 1987, 423 p. 